\title{
Penggalian Riwayat dan Nasihat Tentang Gaya Hidup Sehat oleh Dokter Pelayanan Primer
}

\author{
History Taking and Doctor's Advice about Healthy Lifestyle by Primary \\ Health Care Physician
}

Yayi Suryo Prabandari

Bagian Ilmu Kesehatan Masyarakat Fakultas Kedokteran Universitas Gadjah Mada

\begin{abstract}
Abstrak
Di Indonesia, sejak lebih dari dua dekade, terjadi transisi epidemiologi. Prevalensi penyakit tidak menular (PTM) meningkat menggeser penyakit menular. Sejak tahun 2004, tiga perilaku hidup bersih sehat (PHBS) terkait PTM, yang meliputi tidak merokok, aktivitas fisik, konsumsi tinggi serat belum memenuhi target. Penelitian ini bertujuan mengetahui penggalian riwayat dan nasihat gaya hidup sehat yang dilaporkan oleh pasien dan dokter. Penelitian dilakukan dengan rancangan potong lintang pada 57 dokter dan 251 pasien puskesmas. Data dikumpulkan dengan kuesioner terstruktur dan wawancara di empat puskesmas di Kota Yogyakarta dan delapan puskesmas di Kabupaten Sleman mulai September 2011 sampai dengan Januari 2012. Hasil penelitian menunjukkan bahwa lebih banyak dokter yang memberikan nasihat tentang gaya hidup sehat daripada menanyakannya. Dokter lebih sering melakukan penggalian riwayat dan nasihat tentang kebiasaan merokok daripada tentang olah raga dan pola makan. Penggalian riwayat dan nasihat yang dilaporkan oleh dokter dan pasien berbeda. Menurut pasien, dokter seharusnya bertanya dan memberi nasihat gaya hidup sehat. Karakteristik dokter tidak berhubungan dengan penggalian riwayat dan nasihat gaya hidup sehat yang dilakukan. Penggalian riwayat tentang hidup sehat menjadi prediktor kuat dalam memberikan nasihat untuk melakukan gaya hidup sehat.

Kata kunci: Gaya hidup sehat, nasihat, penggalian riwayat, puskesmas
\end{abstract}

\footnotetext{
Abstract

Epidemiological transition has been occurred in Indonesia in the last two decades. The increasing prevalence of non communicable disease (NCD) has shifted the communicable disease. This pattern has been predicted since the 2004. National health survey reported that the Indonesian' clean and healthy behavior (PHBS) related to NCD, namely, not smoking, exercise and high fiber diet were still far from the target. The role of physician, particularly primary health care is crucial to overcome those health problems. This cross sectional study aimed to assess history taking and advice
}

on healthy life style reported by patient and physician. Participants were 57 physicians and 251 patients of primary health care (Puskesmas). Data were collected by structured questionnaires and interviews at 4 Puskesmas in Yogyakarta City and at 8 Puskesmas in Sleman District, started between September 2011 and January 2012. The results showed that physicians more carried out health advice on healthy life style than ask about them. Patients and physicians reported differently in the history taking and advice on healthy life style. Physician was more asking and advice about smoking habits than exercise and high fiber diet. Characteristics of physicians did not correlate with history taking and advice of healthy lifestyle. History taking of healthy life style was a strong predictor to conduct advice on healthy life style.

Keywords: Healthy life style, advice, history taking, primary health care

\section{Pendahuluan}

World Health Organization (WHO) melaporkan bahwa penyakit tidak menular (PTM) merupakan penyebab kematian terbesar di dunia. ${ }^{1}$ Pada tahun 2008 , lebih dari 36 juta orang meninggal dunia akibat PTM, meliputi penyakit kardiovaskular (48\%), kanker $(21 \%)$, penyakit respiratori kronis $(12 \%)$, dan diabetes $(12 \%)$. Sembilan juta lebih kematian yang terjadi sebelum usia 60 tahun seharusnya dapat dicegah. Di negara berkembang, kematian dini PTM terjadi pada 22\% laki-laki dan 35\% perempuan. Di Indonesia, PTM diperkirakan berkontribusi $64 \%$ terhadap penyebab kematian yang indentik dengan pola yang terjadi di dunia, sekitar 30\% kematian disebabkan penyakit kardiovaskular, 13\% karena kanker

Alamat Korespondensi: Yayi Suryo Prabandari, Bagian Ilmu Kesehatan Masyarakat FK Universitas Gadjah Mada, Gd. IKM Lt. 3, Jl. Farmako Sekip Utara Yogyakarta 55281, Hp.0811251064, e-mail: pyayisuryo@yahoo.com 
$7 \%$ penyakit respiratori dan $3 \%$ diabetes. $^{2}$ Prevalensi PTM terbukti telah menyusul prevalensi penyakit menular. Stroke merupakan PTM yang tertinggi $(26,9 \%)$, disusul hipertensi $(12,3 \%)$, dan diabetes $(10,2 \%)$ yang setara dengan prevalensi tuberkulosis $(27,8 \%)$, penyakit hati $(19,1)$, dan pneumonia $(14,4 \%){ }^{3}$

Pada 1986 - 2007, penyakit penyebab kematian tertinggi di Indonesia adalah penyakit infeksi. Sejak tahun 1995, proporsi tersebut bergeser ke penyakit sistem sirkulasi. Pada periode 1986 - 1992, proporsi penyakit endokrin meningkat dua kali lipat dan dalam kurun waktu 21 tahun, menjadi lima kali lipat. Sebaliknya, penyakit sistem pernapasan mulai menurun, digantikan dengan penyakit neoplasma, sistem pencernaan, dan cedera. ${ }^{4}$ Pergeseran penyakit infeksi dan peningkatan tajam PTM, mengantarkan Indonesia pada tripple burden, meliputi prevalensi penyakit menular yang dapat dicegah belum menurun tajam; PTM mengalami peningkatan yang diikuti masalah kesehatan baru seperti Avian flu, HIV/ AIDS yang muncul dan meningkat pesat; dan sistem jaminan kesehatan nasional baru dilaksanakan pada awal tahun 2014, sementara sistem pemeliharaan kesehatan untuk mencegah dan mengendalikan PTM belum terkelola optimal. ${ }^{4}$

Pada dasarnya, faktor risiko PTM dapat dihindari dan dikendalikan. ${ }^{5}$ Faktor risiko utama penyebab kematian global adalah hipertensi yang menjadi penyebab $13 \%$ kematian global, diikuti perilaku dan gaya hidup, meliputi penggunaan tembakau ( $9 \%)$, peningkatan glukosa darah $(6 \%)$, aktivitas fisik rendah $(6 \%)$, serta kelebihan berat badan dan obesitas $(5 \%)$. Berbagai faktor risiko tersebut juga ditemukan di Indonesia, meliputi hipertensi (31,7\%), gula darah terganggu $(10,2 \%)$, dan Diabetes Melitus $(5,7 \%){ }^{3}$ Pada periode $1995-2007$, prevalensi pengguna tembakau dan rokok di Indonesia tidak pernah menurun, bahkan meningkat sekitar 7\%.6 Pada 1995, prevalensi perokok di Indonesia mencapai $27,2 \%$, laki-laki $(53,9 \%)$ dan perempuan $(1,7 \%)$. Pada tahun 2007, meningkat menjadi $34,7 \%$ meliputi laki-laki $65,9 \%$ dan perempuan $4,2 \% .^{7}$ Terakhir, pada 2011 , prevalensi perokok laki-laki sekitar $67 \%$ dan perempuan $4,5 \%$ dan total sekitar $36,1 \%$. Selama periode 15 tahun, proporsi laki-laki dan perempuan yang kurus menurun signifikan, sedangkan berat badan lebih meningkat hampir dua kali lipat. Penduduk Indonesia yang kurang makan sayur dan buah dilaporkan sekitar 93,6\% dan aktivitas fisik kurang sekitar $48,2 \% .^{8}$

Di Indonesia, pergeseran pada penyakit gaya hidup juga mendorong pergeseran pada penelusuran riwayat penyakit dan nasihat dokter. Penelusuran perilaku berisiko, kebiasaan dan gaya hidup menjadi bagian langkah penelusuran riwayat penyakit pasien. ${ }^{9}$ Nasihat tentang risiko kesehatan berhubungan dengan penyakit karena pasien berharap mendapatkan nasihat. ${ }^{10}$ Di negara maju, nasihat dokter tentang gaya hidup sehat merupakan faktor esensial mencegah PTM dan meningkatkan kesehatan masyarakat. ${ }^{11}$ Namun, hasil penelitian di Yogyakarta, tahun 2003, terhadap 447 dokter menemukan sekitar $72 \%$ dokter tidak rutin menanyakan dan memberi nasihat tentang kebiasaan pasien tersebut. ${ }^{12}$ Dokter hanya kadang-kadang menanyakan riwayat merokok pasien, yang banyak dilakukan dokter wanita di puskesmas. Hanya sekitar 10\% pasien yang menyatakan ditanya oleh dokter tentang rokok. Pertanyaan dokter tersebut hanya dilakukan pada pasien yang dicurigai menderita penyakit tertentu, seperti gangguan pernapasan dan sakit jantung. Penelusuran gaya hidup yang lain, seperti aktivitas fisik, pola makan, pola istirahat, dan tekanan hidup belum banyak dilaporkan.

Dokter di fasilitas pelayanan primer merupakan ujung tombak pelayanan kesehatan di Indonesia, mereka seharusnya memberikan nasihat tentang hidup sehat. Di Eropa, dokter pelayanan primer berperan penting mendiskusikan gaya hidup dengan pasien. ${ }^{11}$ Nasihat sederhana dapat meningkatkan frekuensi berhenti merokok dan mempertahankan kondisi tidak merokok selama 12 bulan. ${ }^{13}$ Sementara, di Amerika, berdasarkan kunjungan dokter dari 184.668.007 pasien yang didiagnosis diabetes tipe 2, hipertensi atau obesitas dan lebih dari 140 juta pasien dengan insulin dan 82 juta pasien yang merokok, lebih dari tiga perempat pasien tidak mendapatkan konseling gaya hidup. ${ }^{14}$ Pasien sangat kurang mendapatkan nasihat perubahan gaya hidup yang membantu memperbaiki status kesehatan meskipun telah menderita penyakit kronis.

Penelitian di Texas, nasihat dan dukungan dokter berhubungan dengan kepercayaan pasien pada dokter yang meningkatkan kepatuhan pasien untuk mengubah perilaku makan. ${ }^{15}$ Agar dapat memberikan nasihat dengan tepat, penelusuran riwayat gaya hidup perlu dilakukan secara mendalam dan lengkap. Penelitian ini bertujuan mendeskripsikan gaya hidup sehat dokter dan pasien, mendeskripsikan pola penggalian riwayat dan nasihat gaya hidup pasien oleh dokter di puskesmas berdasar laporan dokter dan pasien dan menguji prediksi karakteristik dan gaya hidup sehat dokter dalam melakukan penggalian riwayat dan nasihat gaya hidup sehat.

\section{Metode}

Penelitian ini adalah bagian dari penelitian pengembangan kapasitas dokter dalam edukasi pasien untuk pengendalian penyakit yang berhubungan dengan gaya hidup di pelayanan primer. Penelitian yang menggunakan rancangan studi potong lintang ini mengamati populasi pasien yang datang dan dokter yang bertugas di sepuluh puskesmas di wilayah Kabupaten Sleman dan Kota Yogyakarta, Daerah Istimewa Yogyakarta pada bulan 
September 2011 sampai dengan Januari 2012. Sampel dokter diambil menggunakan metode sampling custer, dan pasien diambil dengan sampling kuota. Sebanyak enam dari 25 puskesmas di Kabupaten Sleman serta empat dari 18 puskesmas di Kota Yogyakarta. Pemilihan puskesmas dilakukan secara proporsional dengan pertimbangan keterwakilan wilayah Kabu paten Sleman dan Kota Yogyakarta.

Data dikumpulkan dengan kuesioner terstruktur, dan dokter mengisi sendiri kuesioner, sementara pasien diwawancara oleh surveyor. Kedua kuesioner diadopsi dari kuesioner perilaku merokok dokter dan masyarakat Quit Tobacco Indonesia (QTI) Fakultas Kedokteran Universitas Gadjah Mada, dan pertanyaan dalam Riset Kesehatan Dasar 2007. Sebelum digunakan, kuesioner diuji keterbacaannya pada dua dokter dan lima masyarakat umum untuk menguji validitas muka. Kuesioner dirangkum oleh ahli Ilmu Kesehatan Masyarakat sebagai expert jugment untuk validitas isi. Pertanyaan dalam kuesioner digunakan untuk menggali fakta, analisis faktor untuk validitas konstruk tidak dilakukan. Setelah diuji keterbacaan dilakukan, bahasa kuesioner kemudian diperbaiki.

Variabel yang diamati adalah karakteristik yang meliputi jenis kelamin, usia dan status perkawinan untuk dokter dan pasien, serta lama bertugas atau praktik untuk dokter. Variabel gaya hidup meliputi perilaku hidup sehat, merokok, olahraga, dan konsumsi serat. Perilaku merokok didasarkan pada definisi merokok satu batang dalam 30 hari terakhir. Olahraga didasarkan pada pertanyaan tentang frekuensi melakukan olahraga, konsumsi serat didasarkan pada frekuensi konsumsi sayur dan buah dalam sehari. Pada dokter juga ditanyakan tentang pengalaman pelatihan keterampilan konseling untuk membantu pasien berhenti merokok dan pelatihan atau pengalaman membantu pasien berhenti merokok. Variabel hasil adalah penggalian riwayat dan nasihat dokter tentang gaya hidup sehat. Penggalian riwayat pada dokter diperoleh melalui pertanyaan, selama konsultasi atau praktik, meliputi kebiasaan dan jumlah atau frekuensi merokok, olahraga, dan konsumsi sayur. Untuk variabel penggalian riwayat pasien, juga ditanya tentang keharusan dokter bertanya tentang kebiasaan merokok, olahraga, dan mengonsumsi buah dan sayur. Nasihat kesehatan diperoleh dari pertanyaan apakah pernah dokter menasihati pasien untuk berhenti merokok, olahraga, dan mengonsumsi buah dan sayur. Data survei dianalisis dengan logistik regresi menggunakan perangkat lunak statistik, lisensi Bagian Ilmu Kesehatan Masyarakat Fakultas Kedokteran Universitas Gadjah Mada. Keputusan statistik menggunakan taraf signifikansi 5\% $(\mathrm{p}<0,05)$. Penelitian ini telah mendapatkan ethical clearance dari Komite Etik Fakultas Kedokteran Universitas Gadjah Mada.

\section{Hasil}

Dokter dan pasien wanita lebih banyak daripada pria, meskipun perbedaan proporsi laki-laki dan perempuan pada pasien tidak terlalu besar. Mayoritas dokter dan pasien menikah, variasi usia pasien lebih besar daripada dokter. Rerata usia dokter adalah 32 tahun dan rerata usia pasien 46 tahun. Rata-rata lama praktik dokter adalah 6,5 tahun dengan interval antara 3 bulan hingga 26 tahun. Gaya hidup sehat dokter dan pasien menunjukkan pola yang hampir serupa, meskipun terdapat perbedaan pada frekuensi melakukan. Seperempat dokter mempunyai keluarga inti yang merokok, sedangkan lebih dari sepertiga pasien mengalami pajanan asap rokok di tempat kerja, dan hampir separuh terpajan asap rokok di rumah (Tabel 1).

Dokter yang tidak pernah berolahraga lebih tinggi daripada yang berolahraga. Sementara itu, frekuensi berolahraga tertinggi pada pasien adalah sebulan sekali dan dokter seminggu sekali. Pasien yang berolahraga lebih dari 3 kali seminggu juga lebih tinggi daripada yang melakukan. Pola konsumsi sayur dan buah menunjukkan sebaliknya. Pasien yang tidak pasti makan sayur setiap hari lebih banyak daripada yang mengonsumsi sayur dan buah lebih dari 3 porsi sehari. Frekuensi dokter yang makan sayur dan buah tertinggi adalah 2 porsi sehari, sementara untuk pasien adalah 1 porsi sehari (Tabel 2).

Sebagian besar dokter menggali riwayat dan nasihat tentang gaya hidup pada pasien, tetapi laporan pasien mengindikasikan sebalikn ya. Sebagian besar pasien melaporkan dokter tidak menggali riwayat dan nasihat tentang gaya hidup. Proporsi dokter yang menggali riwayat dan nasihat gaya hidup terbanyak meliputi kebiasaan merokok, aktivitas fisik dan konsumsi sayur dan buah. Pasien melaporkan sebaliknya, bahwa urutan terbanyak dokter melakukan penggalian riwayat dan nasihat adalah konsumsi sayur buah, aktivitas fisik dan merokok. Pasien juga berpendapat bahwa dokter seharusnya melakukan penggalian riwayat gaya hidup sehat dengan urutan proporsi terbanyak serupa (Tabel 3).

Karakteristik dokter bukan prediktor penggalian riwayat karena seluruh variabel karakteristik tidak berhubungan bermakna dengan penggalian riwayat untuk kebiasaan merokok, olahraga, dan konsumsi sayur dan buah. Pada variabel gaya hidup, perilaku merokok dok-

Tabel 1. Karakteristik Sampel Penelitian

\begin{tabular}{llllll}
\hline \multirow{2}{*}{ Karakteristik } & Kategori & \multicolumn{2}{c}{ Dokter } & \multicolumn{2}{c}{ Pasien } \\
\cline { 3 - 6 } & & $\mathbf{n}$ & $\%$ & $\mathbf{n}$ & $\%$ \\
\hline \multirow{2}{*}{ Jenis kelamin } & Laki-laki & 11 & 19,3 & 111 & 44,2 \\
& Perempuan & 46 & 80,7 & 140 & 55,8 \\
Status perkawinan & Menikah & 49 & 84,2 & 189 & 75,7 \\
& Tidak menikah & 9 & 15,8 & 42 & 16,7 \\
& Janda/duda & & & 20 & 0,8 \\
\hline
\end{tabular}


Tabel 2. Gaya Hidup Sehat Dokter dan Pasien

\begin{tabular}{|c|c|c|c|c|c|}
\hline \multirow{2}{*}{ Gaya Hidup } & \multirow{2}{*}{ Kategori } & \multicolumn{2}{|c|}{ Dokter } & \multicolumn{2}{|c|}{ Pasien } \\
\hline & & $\mathbf{n}$ & $\%$ & $\mathbf{n}$ & $\%$ \\
\hline \multicolumn{6}{|l|}{ Perilaku merokok } \\
\hline \multirow[t]{2}{*}{ Dalam 30 hari terakhir } & Ya & 1 & 1,8 & 39 & 16,3 \\
\hline & Tidak & 56 & 98,2 & 199 & 85,7 \\
\hline \multirow[t]{3}{*}{ Suami atau istri merokok } & Ya & 14 & 24,6 & & \\
\hline & Tidak & 38 & 66,7 & & \\
\hline & Saya belum menikah & 5 & 8,7 & & \\
\hline \multirow{2}{*}{ Pajanan asap rokok } & Rumah & & & 98 & 37,8 \\
\hline & Tempat kerja & & & 107 & 42,6 \\
\hline \multirow[t]{5}{*}{ Olahraga } & Tidak & 12 & 21,1 & 18 & 7,2 \\
\hline & 1x sebulan & 10 & 17,5 & 104 & 41,8 \\
\hline & 1x seminggu & 22 & 38,6 & 43 & 17,1 \\
\hline & $3 x$ seminggu & 8 & 14,0 & 37 & 14,7 \\
\hline & Lebih dari $3 x$ seminggu & 5 & 8,8 & 47 & 18,7 \\
\hline \multirow[t]{5}{*}{ Konsumsi sayur dan buah } & Tidak setiap hari & 1 & 12,3 & 45 & 17,9 \\
\hline & 1 porsi sehari & 15 & 26,3 & 72 & 28,7 \\
\hline & 2 porsi sehari & 18 & 31,6 & 61 & 24,3 \\
\hline & 3 porsi sehari & 15 & 26,3 & 68 & 27,1 \\
\hline & Lebih dari 3 porsi sehari & 2 & 3,5 & 4 & 1,6 \\
\hline
\end{tabular}

Keterangan : proporsi tidak mencapai $100 \%$ karena ada missing data

Tabel 3. Penggalian Riwayat dan Pemberian Nasihat Tentang Gaya Hidup Sehat Menurut Dokter dan Pasien

\begin{tabular}{|c|c|c|c|c|c|c|c|c|}
\hline & \multirow{2}{*}{ Variabel } & \multirow{2}{*}{ Kategori } & \multicolumn{2}{|c|}{ Merokok (\%) } & \multicolumn{2}{|c|}{ Olahraga (\%) } & \multicolumn{2}{|c|}{ Konsumsi Serat $(\%)$} \\
\hline & & & Dokter & Pasien & Dokter & Pasien & Dokter & Pasien \\
\hline \multirow{11}{*}{$\begin{array}{l}\text { Penggalian riwayat terkait } \\
\text { gaya hidup sehat }\end{array}$} & \multirow{5}{*}{$\begin{array}{l}\text { Kebiasaan atau gaya } \\
\text { hidup pasien }\end{array}$} & Tidak pernah & 1,8 & 83,3 & 3.6 & 82,9 & 5.3 & 67,3 \\
\hline & & $\mathrm{Ya}$ & & 12,0 & & 16,3 & & 31,5 \\
\hline & & Kadang-kadang & 40,4 & & 67.9 & & 63.2 & \\
\hline & & Hampir selalu & 42,1 & & 21.4 & & 24.6 & \\
\hline & & Selalu & 15,8 & & 7 & & 7.0 & \\
\hline & \multirow{4}{*}{$\begin{array}{l}\text { Jumlah (rokok) atau } \\
\text { frekuensi (olahraga } \\
\text { dan makan sayur) }\end{array}$} & Tidak pernah & 0 & & 1.8 & & 7.4 & \\
\hline & & Kadang-kadang & 46,4 & & 67.3 & & 70.4 & \\
\hline & & Hampir selalu & 37,5 & & 23.6 & & 16.7 & \\
\hline & & Selalu & 16,1 & & 7.3 & & 5.6 & \\
\hline & \multirow{7}{*}{$\begin{array}{l}\text { Keharusan dokter menanyakan } \\
\text { atau menggali gaya hidup sehat } \\
\text { Memberikan nasihat } \\
\text { tentang gaya hidup }\end{array}$} & Ya & & 62,5 & & 71,3 & & 78,1 \\
\hline & & Tidak & & 33,5 & & 27,3 & & 20,7 \\
\hline \multirow{5}{*}{$\begin{array}{l}\text { Pemberian nasihat tentang } \\
\text { gaya hidup sehat }\end{array}$} & & Tidak pernah & 0,0 & 79,7 & 0,0 & 67,7 & & 60,2 \\
\hline & & $\mathrm{Ya}$ & & 12,0 & & 31,5 & & 38,6 \\
\hline & & Kadang-kadang & 23,2 & & 45,5 & & 50,9 & \\
\hline & & Hampir selalu & 41,1 & & 41,8 & & 35,1 & \\
\hline & & Selalu & 35,7 & & 12,7 & & 8,8 & \\
\hline
\end{tabular}

ter tidak dianalisis karena dokter yang merokok sedikit. Dokter yang berolahraga lebih dari tiga kali seminggu berpeluang empat setengah kali lebih besar $(\mathrm{OR}=4,54$; $95 \% \mathrm{CI}=1,27-16,16)$ untuk menggali riwayat kebiasaan olah raga daripada dokter yang berolahraga kurang dari tiga kali seminggu. Untuk dokter, merasa berpengalaman membantu berhenti merokok berpeluang empat kali lebih besar ( $\mathrm{OR}=4,17 ; 95 \% \mathrm{CI}=1,21-14,39)$ untuk menggali riwayat kebiasaan merokok pasien daripada yang tidak merasa pengalaman. Pengalaman pelatihan konseling berhenti merokok tidak berhubungan dengan penggalian riwayat merokok pasien (Tabel 4).

Karakteristik dokter bukan merupakan prediktor melakukan nasihat karena seluruh variabel karakteristik tidak berhubungan bermakna dengan nasihat kebiasaan merokok, olahraga, dan konsumsi sayur dan buah. Variabel gaya tidak dapat dianalisis karena dokter yang merokok sedikit dan variabel gaya hidup bukan prediktor dokter menasihati gaya hidup sehat. Demikian pula dengan perasaan memiliki pengalaman pelatihan dan pengalaman dilatih bukan prediktor bagi dokter untuk menasihati gaya hidup sehat (Tabel 5).

Penggalian riwayat merupakan prediktor yang kuat bagi dokter untuk melakukan nasihat tentang gaya hidup sehat. Dokter yang melakukan penggalian riwayat gaya hidup sehat meliputi perilaku merokok, olahraga, dan konsumsi buah dan sayur berpeluang 26 sampai 37 kali melakukan nasihat gaya hidup sehat daripada mereka 
Tabel 4. Prediktor Dokter Melakukan Penggalian Riwayat untuk Perilaku Merokok, Olahraga, dan Konsumsi Serat

\begin{tabular}{|c|c|c|c|c|c|c|c|c|}
\hline \multirow{2}{*}{ Penggalian Riwayat } & \multirow{2}{*}{ Variabel } & \multirow{2}{*}{ Kategori } & \multicolumn{2}{|c|}{ Merokok } & \multicolumn{2}{|c|}{ Olahraga } & \multicolumn{2}{|c|}{ Konsumsi Serat } \\
\hline & & & OR & 95\% CI & OR & 95\% CI & OR & 95\% CI \\
\hline \multirow[t]{6}{*}{ Karakteristik } & \multirow[t]{2}{*}{ Usia (tahun) } & $<30$ & 1,00 & & 1,00 & & 1,00 & \\
\hline & & $\geq 30$ & 0,77 & $0,26-2,25$ & 1,09 & $0,34-3,56$ & 0,41 & $0,12-1,35$ \\
\hline & \multirow[t]{2}{*}{ Jenis kelamin } & Laki-laki & 1,00 & & 1,00 & & 1,00 & \\
\hline & & Perempuan & 1,18 & $0,31-4,50$ & 0,38 & $0,10-1,45$ & 2,4 & $0,47-12,21$ \\
\hline & \multirow[t]{2}{*}{ Lama praktik } & $<5$ & 1,00 & & 1,00 & & 1,00 & \\
\hline & & $\geq 5$ & 0,57 & $0,18-1,53$ & 0,74 & $0,23-2,39$ & 0,27 & $0,08-0,88$ \\
\hline \multirow[t]{6}{*}{ Gaya hidup } & \multirow[t]{2}{*}{ Merokok } & $\mathrm{Ya}$ & 1,00 & & 1,00 & & 1,00 & \\
\hline & & Tidak & NA & & NA & & NA & \\
\hline & \multirow[t]{2}{*}{ Olahraga } & $<3 \mathrm{x} /$ hari & 1,00 & & 1,00 & & 1,00 & \\
\hline & & $\geq 3 x /$ hari & 1,88 & $0,50-7,01$ & $4,54 *$ & $1,27-16,16$ & 0,58 & $0,14-2,44$ \\
\hline & \multirow[t]{2}{*}{ Konsumsi serat } & $<3 \mathrm{x} /$ hari & 1,00 & & 1,00 & & 1,00 & \\
\hline & & $\geq 3 x /$ hari & NA & & 2,67 & $0,17-42,15$ & 2,24 & $0,14-36,31$ \\
\hline \multicolumn{2}{|c|}{ Pernah mengikuti pelatihan } & Tidak & 1,00 & & & & & \\
\hline \multicolumn{2}{|c|}{ konseling berhenti merokok } & Ya & 2,47 & $0,74-8,21$ & & & & \\
\hline \multirow{2}{*}{\multicolumn{2}{|c|}{$\begin{array}{l}\text { Merasa memiliki pengalaman } \\
\text { untuk bantu berhenti merokok }\end{array}$}} & Tidak & 1,00 & & & & & \\
\hline & & Ya & $4,17 *$ & $1,21-14,39$ & & & & \\
\hline
\end{tabular}

Keterangan : $\mathrm{p}<0,05, \mathrm{NA}=$ not available, karena ada sel yang kosong

Tabel 5. Prediktor Dokter Memberikan Nasihat untuk Perilaku Merokok, Olahraga, dan Konsumsi Serat

\begin{tabular}{|c|c|c|c|c|c|c|c|c|}
\hline \multirow{2}{*}{ Penggalian Riwayat } & \multirow{2}{*}{ Variabel } & \multirow{2}{*}{ Kategori } & \multicolumn{2}{|c|}{ Merokok } & \multicolumn{2}{|c|}{ Olahraga } & \multicolumn{2}{|c|}{ Konsumsi serat } \\
\hline & & & OR & $\mathbf{9 5} \% \mathrm{CI}$ & OR & 95\% CI & OR & 95\% CI \\
\hline \multirow[t]{6}{*}{ Karakteristik } & Usia (tahun) & $<30$ & 1,00 & & 1,00 & & 1,00 & \\
\hline & & $\geq 30$ & 1,40 & $0,40-5,00$ & 2,00 & $0,68-5,87$ & 1,15 & $0,40-3,30$ \\
\hline & Jenis kelamin & Laki-laki & 1,00 & & 1,00 & & 1,00 & \\
\hline & & Perempuan & 1,19 & $0,30-5,40$ & 1,43 & $0,38-5,40$ & 4,50 & $0,90-21,3$ \\
\hline & Lama praktik & $<5$ & 1,00 & & 1,00 & & 1,00 & \\
\hline & & $\geq 5$ & 0,9 & $0,30-3,20$ & 1,1 & $0,40-3,10$ & 0,7 & $0,20-2,00$ \\
\hline \multirow[t]{6}{*}{ Gaya hidup } & Merokok & $\mathrm{Ya}$ & 1,00 & & 1,00 & & 1,00 & \\
\hline & & Tidak & NA & & NA & & NA & \\
\hline & Olahraga & $<3 \mathrm{kali} /$ minggu & 1,00 & & 1,00 & & 1,00 & \\
\hline & & $\geq 3 \mathrm{kali} / \mathrm{minggu}$ & 1,1 & $0,20-4,80$ & 1,60 & $0,40-5,70$ & 0,80 & $0,21-2,70$ \\
\hline & Konsumsi serat & $<3$ kali/hari & 1,00 & & 1,00 & & 1,00 & \\
\hline & & $\geq 3 \mathrm{kali} / \mathrm{hari}$ & NA & & 2,67 & $0,17-42,15$ & 2,24 & $0,14-36,31$ \\
\hline \multicolumn{2}{|c|}{ Pernah mengikuti pelatihan } & Tidak & 1,00 & & & & & \\
\hline \multicolumn{2}{|c|}{ konseling berhenti merokok } & Ya & 1,96 & $0,50-8,10$ & & & & \\
\hline \multirow{2}{*}{\multicolumn{2}{|c|}{ Merasa memiliki pengalaman }} & Tidak & 1,00 & & & & & \\
\hline & & $\mathrm{Ya}$ & 3,92 & $0,80-18,50$ & & & & \\
\hline
\end{tabular}

Keterangan : $\mathrm{p}<0,05, \mathrm{NA}=$ not available, karena ada sel yang kosong

yang tidak melakukan. Hasil OR yang tinggi ini dapat terjadi dengan melihat lebih cermat secara deskriptif pada jumlah total dokter yang melakukan penggalian riwayat dan nasihat tentang gaya hidup sehat. Dokter melakukan nasihat tentang gaya hidup sehat lebih banyak daripada yang melakukan penggalian riwayat (Tabel 6).

\section{Pembahasan}

Hanya seorang dokter yang merokok di antara 57 dokter dan $16,3 \%$ pasien adalah perokok. Proporsi pe-rokok pada pasien di bawah angka nasional mungkin disebabkan oleh sebagian besar partisipan penelitian adalah wanita. Ternyata dari 39 orang yang merokok, hanya seorang yang wanita dan sekitar 35\% pasien pria merokok dalam 30 hari terakhir. Angka ini masih di bawah angka perokok laki-laki nasional (> $60 \%) .3,7$

Dokter yang diharapkan menjadi tokoh panutan perilaku kesehatan, ternyata perilaku yang berhubungan dengan penyakit PTM seperti olahraga dan konsumsi sayur dan buah, masih di bawah kriteria yang ditetapkan. Menjadi panutan diperlukan untuk membentuk perilaku. ${ }^{16}$ Kebiasaan olahraga dapat menjadi faktor pelindung bagi PTM apabila dilakukan minimal tiga kali per minggu dengan durasi minimal 30 menit, atau durasi 20 menit untuk olahraga berat. Dokter yang berolah raga rutin tiga kali per minggu adalah sekitar 14\%, dan yang melakukan lebih dari tiga kali seminggu hanya $8,5 \%$ jauh lebih ren- 
Tabel 6. Penggalian Riwayat Terkait Gaya Hidup Sehat Sebagai Prediktor Pemberian Nasihat Tentang Gaya Hidup Sehat

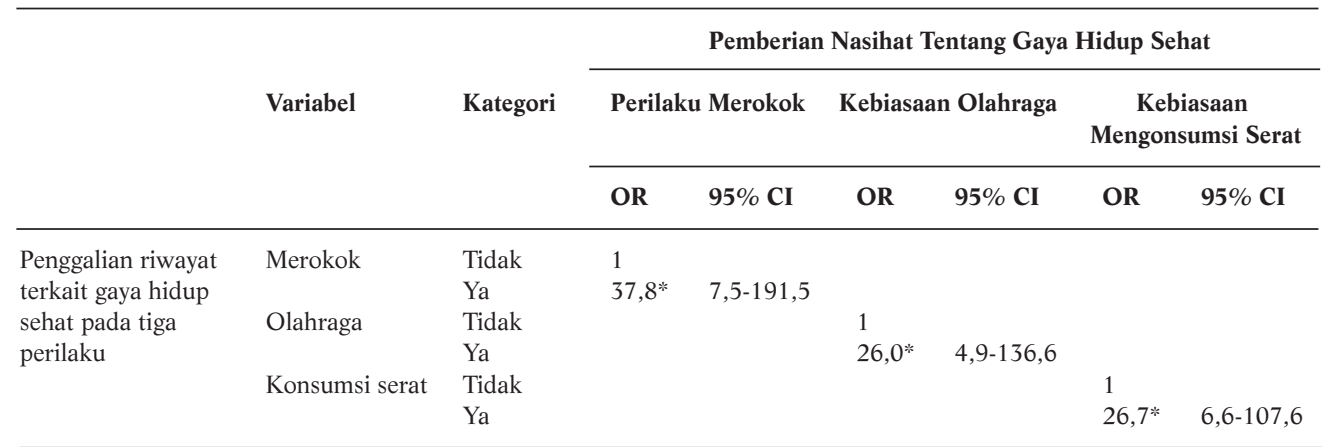

Keterangan : *p $<0,05$

dah dari pasien (18,7\%). Prevalensi yang belum melakukan olahraga sesuai kriteria adalah $48,2 \%$ dan Riskesdas 2013 melaporkan sebanyak 26,1\% penduduk Indonesia kurang melakukan aktivitas fisik. 3,8 Di Estonia, sekitar $92 \%$ dokter keluarga melakukan olah raga dalam waktu 7 hari terakhir dengan intensitas moderat dan tinggi. ${ }^{17}$ Dokter RS di Michigan sekitar 65,4\% melakukan olah raga empat kali atau lebih dalam seminggu, kebiasaan olahraga pada residen tersebut menunjukkan angka yang hampir sama dengan hasil penelitian ini $(18,6 \%) .18$

Pedoman umum gizi seimbang (PUGS) mengategorikan konsumsi buah dan sayur kurang jika kurang dari lima kali per hari. ${ }^{19}$ Berdasar kriteria tersebut, lebih dari 95\% dokter dan pasien dikategorikan konsumsi buah dan sayur rendah. Pada tahun 2007, sekitar 93,6\% penduduk Indonesia kurang konsumsi buah dan sayur dan angka ini belum berubah banyak di tahun 2013, yaitu sebanyak 93,5\%.3,8 Konsumsi sayur dan buah dokter di RS Michigan, sebagian besar mengonsumsi rata-rata 2,6 sayur dan 2,2 porsi perhari, residen rata-rata mengonsumsi 2,1 porsi sayur dan 1,7 porsi buah. ${ }^{18,19}$

Deskripsi gaya hidup sehat yang meliputi tidak merokok, olahraga teratur dan terukur serta konsumsi tinggi serat dokter pelayanan primer dalam penelitian ini yang belum seperti kriteria standar menarik untuk dikaji lebih mendalam. Pada penelitian terdahulu, dokter pelayanan primer yang mempraktikkan gaya hidup sehat lebih memantau dan memberikan nasihat tentang gaya hidup sehat pada pasien dibandingkan dengan dokter spesialis atau dokter yang kurang sehat. ${ }^{20}$ Di Amerika, dokter dengan indeks massa tubuh (IMT) normal lebih percaya diri memberikan nasihat tentang pengaturan pola makan dan konseling olahraga daripada dokter IMT lebih atau obesitas.

Mendasari pentingnya dokter mempunyai gaya hidup sehat, asosiasi mahasiswa kedokteran Amerika mengadvokasi dan memasukkan kurikulum promosi kesehatan personal dan mengintegrasikan program promosi kesehatan di dalam kurikulum prevensi klinis. ${ }^{20}$ Bagian
Kedokteran Keluarga Fakultas Kedokteran Universitas Georgetown di Amerika juga mempunyai program "Well being for you and your patient". Mahasiswa tahun pertama diberikan materi tentang cara untuk meningkatkan kesehatan, fisik, dan psikologis. Kesiapan dokter memberdayakan hidup sehat pasien diawali dengan aplikasi hidup sehat oleh dokter. ${ }^{21}$

Pada penelitian ini, hanya sekitar $15,8 \%$ dokter yang selalu bertanya tentang perilaku merokok pasien, selebihnya sekitar $42,1 \%$ hampir selalu bertanya tentang perilaku merokok pasien. Dengan demikian, hampir 58\% dokter rutin bertanya tentang perilaku merokok pasien. Dokter yang secara rutin menanyakan jumlah rokok adalah sekitar 53\% dan dokter yang menasihati secara rutin pasien supaya berhenti merokok adalah sekitar $77 \%$. Laporan pasien menunjukkan hasil yang berbeda, hanya $12 \%$ dokter yang menanyakan dan menasihati kebiasaan merokok mereka. Penelitian lain melaporkan bahwa $77 \%$ dokter tidak rutin menanyakan kebiasaan merokok pasien dan menasihati kebiasaan tersebut dan hanya $10 \%$ pasien melaporkan ditanya kebiasaan merokok oleh dokter. ${ }^{12}$

Peningkatan proporsi dokter yang menggali riwayat dan nasihat perilaku merokok karena sejak tahun 2009, Dinas Kesehatan Kota Yogyakarta dan Kabupaten Sleman gencar melakukan program-program pengendalian tembakau. Hal ini terkait dengan dana hasil bagi cukai hasil tembakau (DBHCHT) yang harus digunakan untuk berbagai program kesehatan pengendalian tembakau, termasuk pelatihan konseling berhenti merokok untuk dokter dan tenaga kesehatan. Pelatihan oleh Dinas Kesehatan Sleman/Yogyakarta bekerja sama dengan Quit Tobacco Indonesia, proyek pengendalian tembakau kerja sama Fakultas Kedokteran Universitas Gadjah Mada dengan Negara India dan Amerika Serikat. Namun, dalam analisis bivariat menunjukkan prediktor kuat untuk penggalian riwayat pasien untuk perilaku merokok adalah perasaan mampu atau berpengalaman membantu berhenti merokok, dan bukan pengalaman dokter meng- 
ikuti pelatihan konseling berhenti merokok. Penggalian riwayat dokter untuk perilaku merokok dalam penelitian ini tidak dipengaruhi oleh karakteristik atau gaya hidup sehat. Tidak ada prediktor yang bermakna untuk melakukan nasihat terkait perilaku merokok.

Dokter yang rutin menanyakan kebiasaan olahraga adalah $28 \%$, sedangkan kebiasaan makan buah dan sayur sekitar 32\% masih di bawah penggalian riwayat kebiasaan merokok. Nasihat tentang kebiasaan olah raga dan konsumsi sayur buah juga masih rendah daripada nasihat tentang rokok (54,5\% dan 43,9\%). Pasien yang pernah ditanya tentang kebiasaan olahraga sekitar $16,3 \%$ dan konsumsi tinggi serat adalah sekitar 31,5\%. Sekitar $31,5 \%$ pasien melaporkan dokter memberi nasihat olahraga dan $38,6 \%$ nasihat konsumsi tinggi serat. Pada dokter, lebih terkonsentrasi menggali riwayat dan nasihat pada perilaku merokok dan kurang memperhatikan perilaku sehat yang lain. Pasien justru melaporkan dokter lebih menanyakan dan melakukan nasihat terkait dengan konsumsi tinggi serat. Pasien juga melaporkan bahwa dokter seharusnya menanyakan gaya hidup sehat. Proporsi tertinggi adalah menanyakan konsumsi tinggi serat, disusul olahraga dan perilaku merokok.

Hasil penelitian pada pasien ini sama dengan penelitian di Canada, terutama untuk nasihat tentang konsumsi tinggi serat. 22 Di Canada 38\% pasien melaporkan telah diberi nasihat untuk pengaturan makan dan $42 \%$ pasien juga telah diberi nasihat tentang olahraga. Penelitian lainnya di Amerika melaporkan bahwa pasien dengan tekanan darah tinggi lebih mendapatkan nasihat untuk pengaturan pola makan daripada nasihat untuk olahraga. ${ }^{23}$ Penelitian di Belanda tahun 1975 - 2008, dokter menanyakan dan mendiskusikan gaya hidup tertentu didasarkan gejala yang dilaporkan pasien. Untuk perilaku merokok adalah pasien dengan gejala respirasi, keluhan umum (pusing, kelelahan, dan perlu medikasi) serta keluhan sirkulasi yang berhubungan dengan jantung dan vaskular. Pasien yang ditanya dan dinasihati tentang pola makan adalah pasien dengan keluhan digestif dan sirkulasi (hipertensi dan jantung) serta pasien yang dinasihat tentang olahraga adalah pasien dengan keluhan muskuloskeletal dan respiratori.

Dokter yang melakukan olahraga tiga kali seminggu atau lebih berpeluang menanyakan kebiasaan olah raga pasien. Sementara, prediktor lain tidak bermakna. Hasil tersebut sama dengan penggalian riwayat dan nasihat untuk perilaku merokok. Satu-satunya prediktor penggalian riwayat olahraga hanya kebiasaan olahraga dokter, dan tidak satu pun prediktor bermakna bagi dokter untuk melakukan nasihat tentang olahraga dan konsumsi tinggi serat. Di Estonia, dokter yang berolahraga lebih banyak yang menasihati gaya hidup sehat. Kurang olahraga dan kurang makan buah sayur merupakan fak- tor risiko berbagai penyakit terkait gaya hidup sehingga penggalian riwayat dokter merupakan entry point strategis untuk pencegahan penyakit terkait gaya hidup. Skrining dini diperlukan untuk pencegahan penyakit terkait gaya hidup, salah satu untuk mencegah diabetes. ${ }^{24}$

Penggalian riwayat dokter merupakan prediktor kuat dalam melakukan nasihat. Proporsi dokter yang melakukan penggalian riwayat dibanding yang melakukan nasihat lebih rendah. Hal ini menggambarkan bahwa beberapa dokter tidak melakukan penggalian riwayat, tetapi langsung memberikan nasihat. Penggalian riwayat penting agar dokter menemukan permasalahan utama dan menggali faktor risiko sebagai dasar nasihat. ${ }^{8}$ Selain penggalian riwayat, dokter perlu berdiskusi dengan pasien sebelum melakukan nasihat. Pasien di Indonesia saat ini membutuhkan hubungan kerjasama dengan dokter, tidak sekadar konsultasi dan diberi nasihat. ${ }^{25}$ Oleh sebab itu, penggalian riwayat dan gaya hidup masih diperlukan dan pasien mengharapkan diskusi dengan dokter sebagai mitra.

Penelitian ini mempunyai keterbatasan dalam generalisasi hasil karena pengambilan sampel yang dilakukan dengan kluster dan puskesmas dipilih secara purposif, meskipun telah mempertimbangkan keterwakilan wilayah. Kuesioner untuk dokter merupakan self-administered dan teknis pelaksanaan tergantung ketersediaan waktu dokter yang menyebabkan prosedur pengisian tidak sama untuk semua dokter sehingga berpeluang bias. Kuesioner digunakan untuk wawancara pasien dan karena kuesioner terstruktur, secara ideal kuesioner dibacakan tanpa mengubah bahasa, tetapi penelitian dilakukan di Yogyakarta, sehingga wawancara pada beberapa pasien dilakukan dengan bahasa Jawa. Alih bahasa langsung di lapangan dapat menimbulkan ketidaksetaraan alih bahasa.

\section{Kesimpulan}

Dokter lebih banyak yang tidak merokok dibanding dengan pasien, dan mengonsumsi tinggi serat lebih daripada pasien. Namun, dokter melakukan olahraga lebih sedikit daripada pasien, frekuensi berolahraga paling banyak seminggu sekali, sedangkan frekuensi olahraga pasien terbanyak sebulan sekali. Agar nasihat tentang gaya hidup dapat lebih mengena sasaran pada pasien atau masyarakat secara umum, dokter disarankan mengaplikasikan gaya hidup sehat. Aplikasi hidup sehat lebih optimal jika mulai dipelajari sejak mahasiswa sehingga disarankan pembelajaran gaya hidup sehat tidak sekedar diajarkan di fakultas kedokteran, tetapi juga harus dilakukan dan dikemas dalam suatu pembelajaran yang tidak memisahkan teori dan praktik.

\section{Saran}

Ada perbedaan penggalian riwayat dan nasihat ten- 
tang gaya hidup yang dilaporkan oleh dokter dan pasien. Sebagian besar dokter melaporkan telah melakukan penggalian riwayat dan nasihat tentang gaya hidup. Sebaliknya, sebagian besar pasien melaporkan bahwa dokter tidak melakukan penggalian riwayat dan nasihat gaya hidup. Berdasarkan hal ini, disarankan pada dokter agar lebih meluangkan waktunya untuk melakukan penggalian riwayat dan nasihat gaya hidup sehat. Jika memungkinkan, konseling hidup sehat masuk dalam jaminan kesehatan sehingga dokter senantiasa melakukan. Dokter juga disarankan tetap terus belajar dan mengasah keterampilan untuk membantu pasien melakukan aplikasi hidup sehat, termasuk berhenti merokok.

\section{Daftar Pustaka}

1. Riley L, Cowan M, Alwan A. Assessing national capacity for the prevention and control of non communicable disease. Geneva: World Health Organization; 2012.

2. Alwan A, Armstrong T, Cowan M, Riley L. NCD country profile. Geneva: WHO; 2012.

3. Badan Penelitian dan Pengembangan Kesehatan Kementerian Kesehatan. Riskesdas 2007. Jakarta: Balitbangkes Kemenkes RI; 2008.

4. Djaya S. Transisi epidemiologi di Indonesia dalam dua dekade terakhir dan implikasi pemeliharaan kesehatan menurut Survei Kesehatan Rumah Tangga, Surkernas, Riskesdas (1986-2007). Buletin Penelitian Kesehatan. 2012; 40(3): 142 - 53.

5. Fertman C, Allensworth DD. Health promotion programs. San Fransisco, USA: Jossey-Bass A Wiley Imprint; 2010.

6. Prabandari YS, Ng N, Padmawati RS. Kawasan tanpa rokok sebagai alternatif pengendalian tembakau-studi efektivitas penerapan kebijakan kampus bebas rokok terhadap perilaku dan status merokok mahasiswa di Fakultas Kedokteran UGM Yogyakarta. Jurnal Manajemen dan Pelayanan Kesehatan. 2010; 12(4): 218-25.

7. Kosen S, Hardjo H, Kadarmanto, Sinha DN, Palipudi KM, Wibisana W, et al. Global adult tobacco survey: Indonesia Report 2011. India: World Health Organization Regional Office for South-East Asia; 2012.

8. Badan Penelitian dan Pengembangan Kesehatan Kementerian Kesehatan. Riskesdas 2013. Jakarta: Balitbangkes Kemenkes RI; 2013.

9. Gleadle J. Penggalian riwayat dan pemeriksaan fisik, terjemahan. Surabaya: Erlangga Medical Series; 2007.

10. Mahvan T, Namdar R, Voorhees K, Smith PC, Flake D. Which smoking cessation interventions work best? The Journal of Family Practice. 2011; 60 (7): 430-1.

11. Noordman J, Verhaak P, van Dulmen S. Discussing patient's lifestyle choices in the consulting room: analysis of GP-patient consultations between 1975and 2008. BMC Family Practice [serial on internet]. 2010 [cited 2013 Dec 30]; 11: 87. Available from: http://www.biomedcentral.com/1471-2296/11/87.

12. Ng N, Prabandari YS, Padmawati RS, Okah F, Haddock CK, Nichter M, et al. Physician assessment of patient smoking in Indonesia: a public health priority. Tobacco Control. 2007; 16(3): 190-6.

13. Lancaster T, Stead LF. Individual behavioral counseling for smoking cessation. Cochrane Database System Review. 2008; (4): CD001292

14. Heaton PC, Frede SM. Patients' need for more counseling on diet, exercise, and smoking cessation: results from the National Abulatory Medical Care Survey. Journal of American Pharmacist Association. 2006; 46 (3): 364-9.

15. Berry LL, Parish JT, Janakiraman R, Russell LO, Couchman GR, Reyburn WL, et al. Patients' commitment to heir primary physician and why it matters. Annals of Family Medicine [serial on internet]. 2008 [Cited on 2013 December 21]; 6(1): 6-13. Available from http:// www.annfamed.org.

16. Glanz K, Rimer BK, Viswanath K. Health Behavior and Health Advice. San Fransisco, USA: Jossey-Bass, a Wiley Imprint; 2008.

17. Suija K, Pechter U, Maaroos J, Kalda R, Ratsep A, Oona M, et al. Physicalactivity of Estonian family doctors and their counselling for a healthy lifestyle: a cross-sectional study. BMC Family Practice [manuscript on internet]. 2010 [cited 2013 December 30]; 11: 48. Available from:http://www.biomedcentral. com/1471-2296/11/48.

18. Howe M, Leidel A, Krishnan S, Weber A, Rubenfire M, Jackson EA. Patient-prelated diet and exercise counseling: do providers' own lifestyle habits matter? Preventive Cardiology. 2010; 13: 180-5.

19. Soekirman, Atmawikarta A, Latief D. Pedoman umum gizi seimbang (Panduan untuk Petugas). Jakarta: Depkes RI Direktorat Jenderal Bina kesehatan Masyarakat Direktorat Gizi Masyarakat; 2003.

20. Cameron D, Katch E, Anderson P, Furlong MA. Healthy doctors, healthy communities. Journal of Ambulatory Care Management. 2004; 27 (4): 328-35.

21. Bleich SN, Bennett WL, Guzune KA, Cooper LA. Impact of physician BMI on obesity care and beliefs. Obesity [serial on internet]. 2012 [cited 2013 Aug 5]; 20: 999-1005. Available from: http://www.nature.com/doifinder/ 10.1038/ oby.2011.402.

22. Sinclair J, Lawson B, Burge F. Which patients receive advice on diet and exercise? Do certain characteristics affect whether they receive such advice? Cannadian Family Physician. 2008; 54: 404-23.

23. Ayala C, Neff LJ, Croft JB, Jeenan NL, Malarcher AM, Hyduk A, et al. Prevalence of self-reported high blood pressure awareness, advice received from health professionals, and actions taken to reduce high blood pressure among US adults, health styles 2002. The Journal of Clinical Hypertension. 2005; 7(9): 513-519.

24. Vaccaro JA, Feaster DJ, Lobar SL, Baum MK, Magnus M, Huffman FG. Medical advice and diabetes self-management reported by MexicanAmerican, Black- and Whitenon-Hispanic adults across the United States. BMC Public Health [manuscript on internet]. 2012 [Cited 2013 Aug 2013]; 12: 185. Available from: http://www. biomedcentral.com/$1471-2458 / 12 / 185$

25. Claramita M, Prabandari YS, Dalen Jv, Vleuten Cv. Developing and validating a guideline on doctor-patient communication for Southeast Asian context. South East Asian Journal of Medical Education. 2010; 4(2): 23-30. 